\title{
Insulin Aspart
}

National Cancer Institute

\section{Source}

National Cancer Institute. Insulin Aspart. NCI Thesaurus. Code C47563.

A recombinant human insulin analog with rapid-acting, blood glucose-lowering activity. Insulin aspart, acting faster than regular human insulin, regulates glucose metabolism by binding to insulin receptors on muscle and fat cells, thereby facilitating the cellular uptake of glucose. This lowers blood glucose levels. At the same time, insulin aspart inhibits the liver's conversion of stored glycogen into glucose, which also contributes to lower blood glucose levels. Insulin aspart also inhibits lipolysis in adipose tissue, inhibits proteolysis, and enhances protein synthesis. ( $\mathrm{NCI05)}$ 